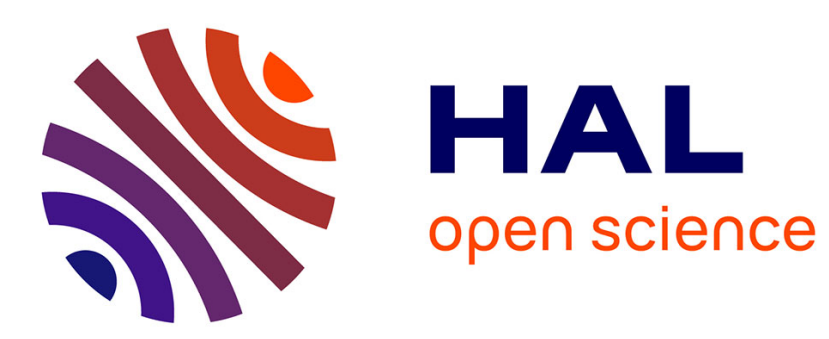

\title{
Enhanced Torque Control of a PMSM Supplied by a Four-Leg Voltage Source Inverter Using the Third Harmonic
}

\author{
Fabien Meinguet, Eric Semail, Johan Gyselinck
}

\section{To cite this version:}

Fabien Meinguet, Eric Semail, Johan Gyselinck. Enhanced Torque Control of a PMSM Supplied by a Four-Leg Voltage Source Inverter Using the Third Harmonic. International Congress on Electrical Machines, Sep 2008, Vilamoura, Portugal. pp.1-6, 10.1109/ICELMACH.2008.4799868 • hal-01107788

\author{
HAL Id: hal-01107788 \\ https://hal.science/hal-01107788
}

Submitted on 21 Jan 2015

HAL is a multi-disciplinary open access archive for the deposit and dissemination of scientific research documents, whether they are published or not. The documents may come from teaching and research institutions in France or abroad, or from public or private research centers.
L'archive ouverte pluridisciplinaire HAL, est destinée au dépôt et à la diffusion de documents scientifiques de niveau recherche, publiés ou non, émanant des établissements d'enseignement et de recherche français ou étrangers, des laboratoires publics ou privés. 


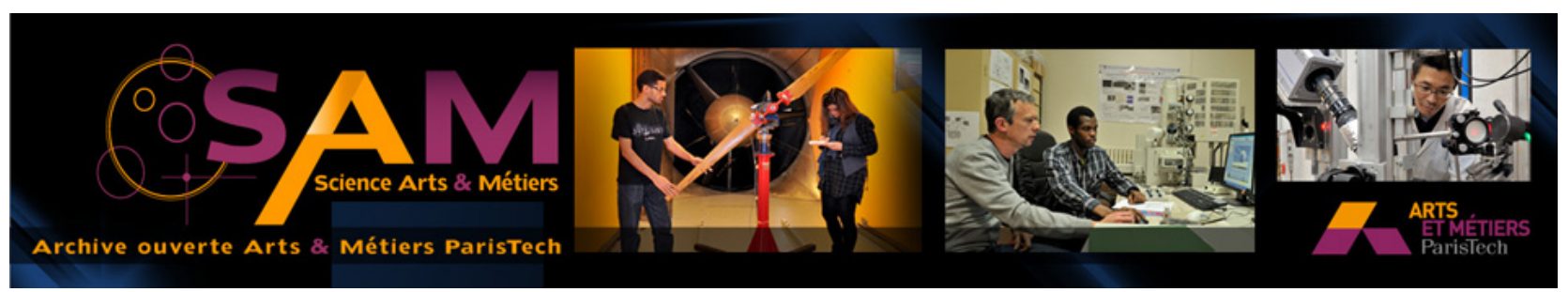

\section{Science Arts \& Métiers (SAM)}

is an open access repository that collects the work of Arts et Métiers ParisTech researchers and makes it freely available over the web where possible.

This is an author-deposited version published in: http://sam.ensam.eu

Handle ID: .http://hdl.handle.net/10985/9259

\section{To cite this version :}

Fabien MEINGUET, Eric SEMAIL, Johan GYSELINCK - Enhanced Torque Control of a PMSM Supplied by a Four-Leg Voltage Source Inverter Using the Third Harmonic - In: International Congress on Electrical Machines, Portugal, 2008-09-06 - 18th International Conference on Electrical Machines - 2008 


\title{
Enhanced Control of a PMSM Supplied by a Four-Leg Voltage Source Inverter Using the Homopolar Torque
}

\author{
Fabien Meinguet*, Eric Semail ${ }^{\S}$, Johan Gyselinck* \\ *BEAMS, Université Libre de Bruxelles, Brussels, Belgium \\ e-mail: \{Fabien.Meinguet, Johan.Gyselinck\}@ulb.ac.be \\ ${ }^{\S}$ L2EP, Ecole Nationale Supérieure d'Arts et Métiers, Lille, France \\ e-mail: Eric.Semail@Lille.ENSAM.fr
}

\begin{abstract}
This paper investigates an electrical drive composed of a four-leg voltage source inverter and a three-phase starconnected surface permanent magnet synchronous machine. The fourth leg of the inverter is clamped to the neutral point of the machine. We find the current references leading to smooth torque and maximum torque per ampere operation in the presence of a third harmonic electromotive force component. We further analyze the advantages of the proposed topology in terms of torque increase and dc-link voltage requirements. Design aspects are briefly discussed.
\end{abstract}

\section{INTRODUCTION}

The industry requires electrical actuators with a high torqueto-mass ratio to reduce the total weight of the embedded equipment, which makes permanent magnet synchronous machines (PMSM) very attractive.

Another requirement of several applications concerns the reliability of the system. To avoid a full-redundant topology, fault-tolerant drives have been investigated for several years [1]-[2]. It has been shown that a four-leg voltage source inverter (VSI) with the fourth leg connected to the neutral point provides fault-tolerance against most of the inverter faults for a three-phase machine [3]-[4].

Efficiency is also an important issue. The maximum torque per ampere (MTPA) strategy has been studied for internal PMSM (IPMSM) in several papers [5]-[6]. In most cases, zero-sequence current is not taken into account because threeterminal star-connected machines are considered. The inverter topology with fourth leg provides an additional degree of freedom (DOF) [7]-[8] allowing to control this zero-sequence current, which combined with the presence of a zero-sequence electromotive force (EMF) component may provide an additionnal torque.

This paper presents a novel control strategy taking advantage of the extra DOF given by the fourth leg of the inverter. First the classic $d q$ current control is introduced for the proposed topology, after what we describe a MTPA strategy assuming that the EMF induced by the magnets only has a first and a third harmonic component. As the homopolar torque is known to be pulsating, the proposed control algorithm is dedicated to minimizing this pulsating torque component. Next we analyze the obtained torque per ampere capacity and the dc-link voltage requirements as a function of the third-tofirst harmonic component ratio of the EMF. The last section presents some enhancements to increase the performance of the drive.

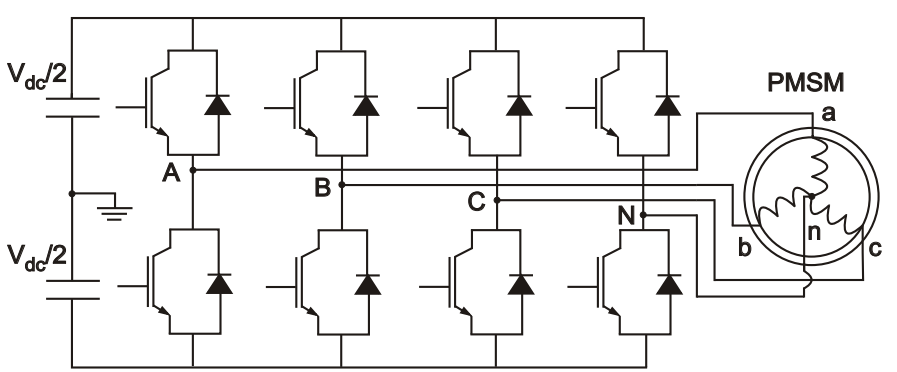

Fig. 1. Drive topology: a four-leg VSI supplying a three-phase SPMSM.

\section{PMSM DRIVE MODEL}

Nowadays PMSMs are widely used, but except for faulttolerant applications it is uncommon to use them with fourleg inverters. In those applications, the fourth leg can either be used as a "back-up leg", aiming to replace a faulty leg, or be connected to the neutral point of the machine allowing a neutral current to flow conferring the possibility to carry on the drive with two active phases. Mostly this fourth leg is only used in the post-fault operation and additional components such as back-to-back thyristors are required to route a current path needed to obtain a convenient rotating field. These additional components require dedicated control and cause extra losses. This is one of the reasons why this paper explores the proposed topology and advantages in the unfaulty mode of operation as well.

In this section we will describe the drive model composed of a three-phase star-connected surface PMSM (SPMSM) and a four-leg inverter as shown in Fig. 1.

\section{A. PMSM model with connected neutral point}

In what follows, we neglect effects of saliency and saturation. Moreover, the EMF induced by the magnets in the stator windings only has a fundamental and a third-harmonic component with synchronized zero crossings. The fourth leg of the inverter is connected to the neutral point of the machine and allows imposing continuously the neutral point voltage $V_{n}$. Then, the model equations in the $a b c$ reference frame are given by:

$$
\left[\begin{array}{c}
V_{a}-V_{n} \\
V_{b}-V_{n} \\
V_{c}-V_{n}
\end{array}\right]=R_{s}\left[\begin{array}{c}
I_{a} \\
I_{b} \\
I_{c}
\end{array}\right]+\left[\begin{array}{ccc}
L & M & M \\
M & L & M \\
M & M & L
\end{array}\right] \frac{d}{d t}\left[\begin{array}{c}
I_{a} \\
I_{b} \\
I_{c}
\end{array}\right]+\left[\begin{array}{c}
E_{a} \\
E_{b} \\
E_{c}
\end{array}\right]
$$




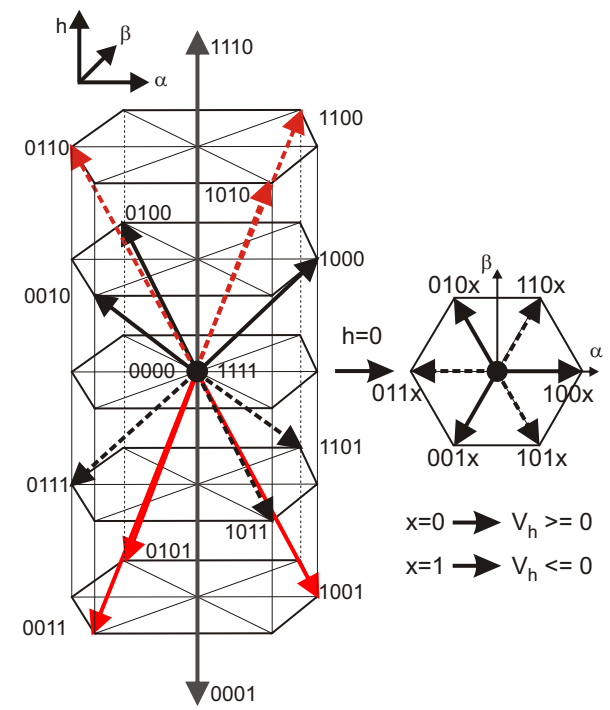

Fig. 2. Four-leg VSI: the 16 space voltage vectors and the projection on the $V_{\alpha \beta}$ plane.

where $R_{s}$ is the stator resistance, $L$ and $M$ are the stator phase self and mutual inductances and $V_{x}, I_{x}$ and $E_{x}$ are the phase-x voltage with respect to a virtual dc-link middle point, the phase-x current and the EMF induced by the magnets in phase-x respectively $(x \in\{a, b, c\}) . I_{n}$ is given by:

$$
I_{n}=-\left(I_{a}+I_{b}+I_{c}\right) .
$$

Applying the Park transformation defined by (3), (4) and (5) to (1), we find the model equations (6), (7) and (8) expressed in the $d q h$ rotor reference frame:

$$
\begin{aligned}
& {\left[X_{d q h}\right]=[P]\left[X_{a b c}\right] \quad ; \quad\left[X_{a b c}\right]=[P]^{-1}\left[X_{d q h}\right]} \\
& {[P]=\frac{2}{3}[R][C] \quad ; \quad[P]^{-1}=[C]^{t}[R]^{t}} \\
& {[R]=\left[\begin{array}{ccc}
\cos \theta_{e} & \sin \theta_{e} & 0 \\
-\sin \theta_{e} & \cos \theta_{e} & 0 \\
0 & 0 & 1
\end{array}\right] \quad ; \quad[C]=\left[\begin{array}{ccc}
1 & -\frac{1}{2} & -\frac{1}{2} \\
0 & \frac{\sqrt{3}}{2} & -\frac{\sqrt{3}}{2} \\
\frac{1}{\sqrt{2}} & \frac{1}{\sqrt{2}} & \frac{1}{\sqrt{2}}
\end{array}\right]} \\
& {\left[\begin{array}{l}
V_{d n} \\
V_{q n} \\
V_{h n}
\end{array}\right]=R_{s}\left[\begin{array}{l}
I_{d} \\
I_{q} \\
I_{h}
\end{array}\right]+\left[\begin{array}{ccc}
L_{d q} & 0 & 0 \\
0 & L_{d q} & 0 \\
0 & 0 & L_{h}
\end{array}\right] \frac{d}{d t}\left[\begin{array}{c}
I_{d} \\
I_{q} \\
I_{h}
\end{array}\right]+\left[\begin{array}{c}
E_{d} \\
E_{q} \\
E_{h}
\end{array}\right]} \\
& L_{d q}=L-M \quad ; \quad L_{h}=L+2 M \quad\left(-\frac{1}{2} L \leq M \leq 0\right) \\
& {\left[\begin{array}{c}
E_{d} \\
E_{q} \\
E_{h}
\end{array}\right]=\omega_{e}\left[\begin{array}{c}
-L_{d q} I_{q} \\
L_{d q} I_{d}+\psi_{1} \\
\sqrt{2} \psi_{3} \sin \left(3 \theta_{e}\right)
\end{array}\right]}
\end{aligned}
$$

where $\theta_{e}$ is the electrical position, $\omega_{e}$ the electrical speed, and $\psi_{1}$ and $\psi_{3}$ the flux linkages related to the first and the third harmonics respectively.

The expression of the instantaneous electromagnetic torque is:

$$
T_{e m}=\frac{3}{2} P\left(\psi_{1} I_{q}+\sqrt{2} \psi_{3} \sin \left(3 \theta_{e}\right) I_{h}\right)
$$

where $P$ is the number of pole pairs.

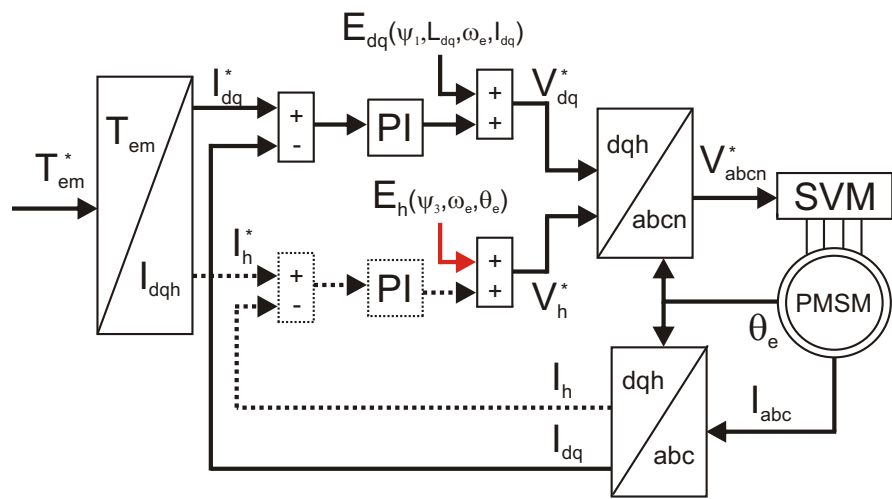

Fig. 3. Control scheme: uninterrupted lines depicts a classic $d q$ control while dashed lines concerns the homopolar current control (MTPA strategy).

\section{B. Four-leg inverter model}

The four-leg inverter posses 4 DOFs, i.e. the upper or bottom switch 'on' or 'off' states. Fig. 2 shows the $2^{4}$ voltage space vectors (VSV) in the $\alpha \beta h$ reference frame fixed to the stator. The four numbers near the vector arrows indicate the state of the $\mathrm{ABCN}$ legs respectively, ' 1 ' meaning that the upper switch is 'on' and ' 0 ' that the bottom switch is 'on'. There are 2 zero vectors, 2 vectors having only a zero sequence component equal to $\pm \sqrt{2} V_{d c}$, and 12 vectors split up equitably into 4 different zero-sequence planes: $V_{h}=-\frac{2}{3}$, $-\frac{1}{3}, \frac{1}{3}$ and $\frac{2}{3}$ of $\sqrt{2} V_{d c}$. The projections of the VSVs in the $\alpha \beta$ plane are also shown in Fig. 2. The projected vectors are strictly equivalent to the VSV of the three-leg inverter as the $\alpha \beta$ components have the same phases and amplitude of $\frac{2}{3} V_{d c}$.

\section{TORQUE CONTROL}

\section{A. Classic control law}

The usual torque control of a PMSM is achieved with the $d q$ Park model and PI controllers as shown in Fig. 3. On the left as input is the torque reference $T_{e m}^{*}$ coming, for example, from a speed loop. This reference is transformed into current references $I_{d}^{*}, I_{q}^{*}$ and $I_{h}^{*}$ thanks to the model equations. The most simple control then only provides a $q$ axis current reference $I_{q}^{*}$ even though it is also posssible to have a non-zero $d$-axis current reference $I_{d}^{*}$ for producing an additional reluctance torque (in case of a rotor having saliency) or if a flux-weakening operation is required, what will not be considered in the following. $I_{q}^{*}$ is then compared to the actual value of the motor $q$-axis current $I_{q}$ and a simple PI controller is used to reach the ideally constant or slowly varying reference. Compensation of the EMF $E_{d q}$ is needed to decouple the $d$ and $q$ axis according to (8) and to obtain the adequate voltage references.

Care should be taken if we want to apply the simple $d q$ control with the considered topology. Indeed to apply a zero homopolar voltage may be harmful for the drive. This can be well understood considering the $d q$ and $h$ electrical equivalent circuits shown in Fig. 4. If $V_{h}=0$, the homopolar circuit behaves as a short-circuited generator and homopolar current is thus only limited by the homopolar impedance that, depending on the machine design, may be low (see section VI). The resulting homopolar torque has a negative average value, is pulsating and then decreases the drive performance. 


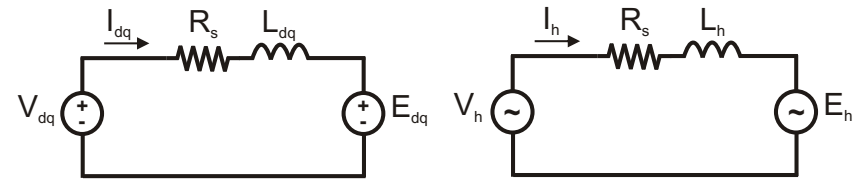

Fig. 4. Equivalent circuits of the machine in the $d q$ and $h$ coordinates.

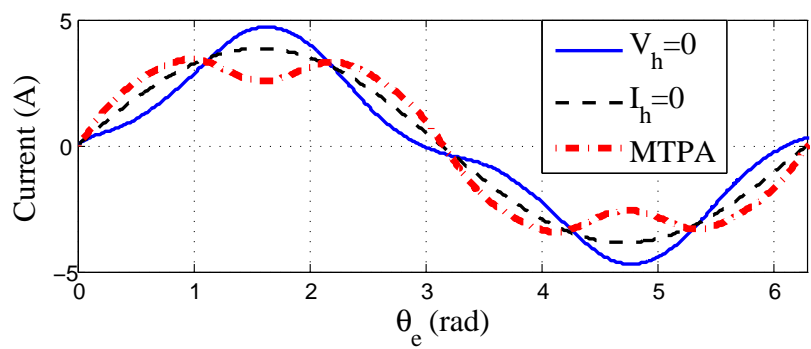

Fig. 5. Comparison of the phase current for three control schemes: $V_{h}=0$, $I_{h}=0$ (classic $d q$ control) and the MTPA strategy.

The solution consists in compensating the homopolar EMF as well, leading to zero homopolar current.

Fig. 5 shows the comparison of the phase current for different control algorithms for the same torque reference. The figure shows that if the homopolar voltage is not considered, i.e. if $V_{h}=0$, a higher peak phase current will flow than with the $I_{h}=0$ control algorithm. This is because the third harmonic current component is approximately in phase with the fundamental instead of to be $180^{\circ}$ phase-shifted as the EMF components.

\section{B. Determination of the MTPA control law}

MTPA strategy has been mainly applied to IPMSMs to take advantage of the reluctance torque. Here as we consider a nonsalient machine, it is obvious that the MTPA strategy consists in finding the $I_{q}^{*}$ and $I_{h}^{*}$ current references that maximize the torque while $I_{d}^{*}$ is kept to zero. As system (6) is decoupled, the $d q h$ coordinates form a 3D orthogonal space and the instantaneous current amplitude $I_{s}$, being representative of the instantaneous Joule losses in the stator windings, can be expressed as:

$$
I_{s}=\sqrt{I_{q}^{2}+I_{h}^{2}}
$$

By substituting (10) in (9), we find:

$$
T_{e m}=k_{1} \sqrt{I_{s}^{2}-I_{h}^{2}}+k_{3}\left(\theta_{e}\right) I_{h}
$$

with $k_{1}=\frac{3}{2} P \psi_{1}$ and $k_{3}=\frac{3}{2} P \sqrt{2} \psi_{3} \sin \left(3 \theta_{e}\right)$. Then deriving (11) with respect to $I_{h}$ and equaling to zero allows to find for a given $\theta_{e}$ :

$$
\frac{I_{h}}{I_{q}}=\frac{k_{3}\left(\theta_{e}\right)}{k_{1}}=\sqrt{2} a \sin \left(3 \theta_{e}\right)
$$

where $a=\frac{\psi_{3}}{\psi_{1}}$ is the ratio of the third-to-first harmonic component of the EMF. As relation (12) is true for each value of $\theta_{e}$, we finally obtain the MTPA current references that satisfy the instantaneous torque reference $T_{e m}^{*}$ :

$$
\left\{\begin{array}{l}
I_{d}^{*}=0 \\
I_{q}^{*}=k\left(\theta_{e}\right) \psi_{1} T_{e m}^{*} \\
I_{h}^{*}=k\left(\theta_{e}\right) \sqrt{2} \psi_{3} \sin \left(3 \theta_{e}\right) T_{e m}^{*}
\end{array}\right.
$$

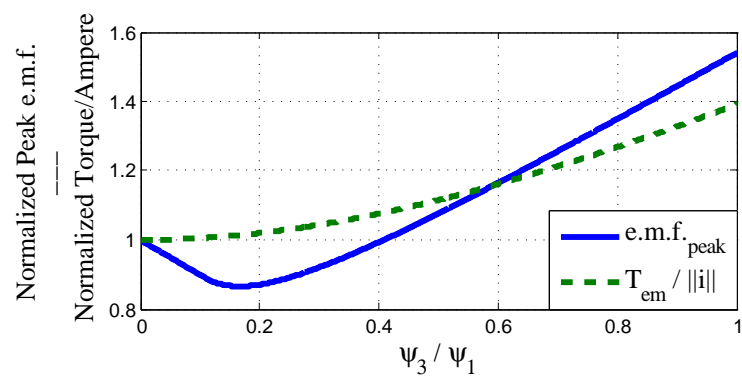

Fig. 6. Normalized peak value of the EMF and torque per ampere as a function of the third-to-first harmonic ratio of the EMF.

where $k\left(\theta_{e}\right)$ is a coefficient that is function of the electrical position and is given by:

$$
k\left(\theta_{e}\right)=\frac{2}{3 P\left(\psi_{1}^{2}+\left(\sqrt{2} \psi_{3} \sin \left(3 \theta_{e}\right)\right)^{2}\right)} .
$$

Fig. 5 shows that the MTPA strategy leads to the lowest peak current. As the torque per ampere depends on $\theta_{e}$, we need to integrate it with respect to $\theta_{e}$ over one period to find an average value that may quantify the torque per ampere gain. Let us call $k_{t, a v g}$ the average torque per ampere over one period of rotation and $k_{t, a v g, p u}$ the normalized value obtained by dividing $k_{t, \text { avg }}$ by the torque constant without third harmonic: $k_{t, \psi_{3}=0}=\frac{3}{2} P \psi_{1}$, thus:

$$
\begin{gathered}
k_{t, a v g}=\frac{1}{2 \pi} \int_{0}^{2 \pi} \frac{T_{e m}}{I_{s}} d \theta_{e} \\
k_{t, a v g, p u}=\frac{1}{2 \pi} \int_{0}^{2 \pi} \sqrt{1+\left(\sqrt{2} a \sin \left(3 \theta_{e}\right)\right)^{2}} d \theta_{e} .
\end{gathered}
$$

Fig. 6 shows the value of $k_{t, a v g, p u}$ as a function of the parameter $a$.

An interpretation is helpful to better understand how the control works. Actually, it is known that homopolar torque is pulsating due to the fact that the homopolar EMF is sinusoidal. So when it crosses zero, the homopolar circuit has no possibility to produce torque. In that case, the required torque is only provided by the $d q$ currents. Otherwise the homopolar circuit is able to contribute to the torque production. The problem consists then in optimizing the torque sharing between both harmonics. This problem has already been studied for polyphase machines where the decomposition in several two-phase equivalent machines leads to more convenient expressions. It is shown in [9] with a vectorial approach that the Joule losses are minimized if the currents are co-linear with the EMF. It is easy to verify that the strategy described by (13) is equivalent since $I_{q}^{*}$ is proportional to $k_{1}$ and $I_{h}^{*}$ to $k_{3}$. The major difference is that the three-phase MTPA strategy leads to position-dependant references that could be troublesome for speed control as we will see in the next section.

\section{Simulation of The MTPA CONTROL LAW}

Simulations of the control law (13) have been realised thanks to Matlab/Simulink. The relevant parameters of the considered motor are given in Table I. The EMF contains $25 \%$ of third harmonic and a small amount of higher harmonics 

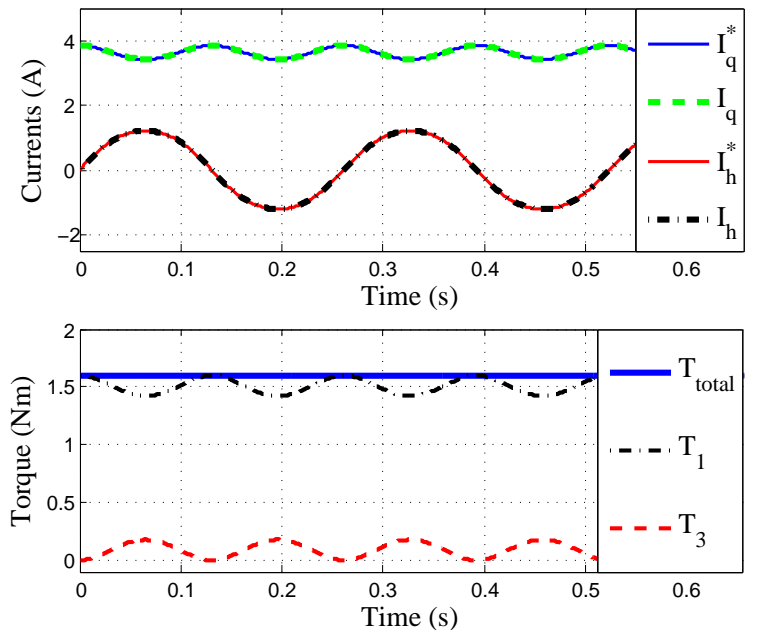

Fig. 7. Top: the $q h$ current references and the real $q h$ currents ; Bottom: EM torque produced by $q$ and $h$ currents and the sum of both ; $T_{e m}^{*}=1.6 \mathrm{Nm}$; $\omega_{m}=1.6 \mathrm{rad} / \mathrm{s}$.

that have been neglected. Current loop controllers have been designed to obtain a bandwidth of $500 \mathrm{~Hz}$.

TABLE I

MOTOR PARAMETERS

\begin{tabular}{|c|c|}
\hline Parameters & Values \\
\hline \hline$L_{d q}(\mathrm{mH})$ & 3.24 \\
\hline$L_{h}(\mathrm{mH})$ & 1.65 \\
\hline$R s(\Omega)$ & 1.1 \\
\hline$\psi_{1}(\mathrm{mWb})$ & 55.4 \\
\hline$\psi_{3}(\mathrm{mWb})$ & 13.9 \\
\hline$P$ & 5 \\
\hline$T_{\text {nom }}(\mathrm{Nm})$ & 1.6 \\
\hline$w_{\text {nom }}(\mathrm{RPM})$ & 10000 \\
\hline
\end{tabular}

Figs. 7 and 8 display the $q h$ currents, the $q h$ current references and the contributions of the $q$ and $h$-axis currents to the total electromagnetic torque for two different mechanical speeds. It shows that the total torque has no ripple as long as the speed is low (cogging torque is neglected). At higher speed ripple may appear because the references are not constant. Indeed, homopolar current reference is sinusoidal and the $q$ axis reference has a sixth harmonic component that counteracts the pulsating torque. Then the controller should have a high enough bandwidth to cope with electrical frequencies up to $\omega_{e}=6 P \omega_{m, \max }$ if torque ripple is unwanted. Ripple is generally unwanted for high performance servodrives, but it is not necessarily the case for speed control applications. To avoid problems caused by PI controllers, more complex control such as sliding mode control could also be applied.

Figs. 9 and 10 show the simulation results obtained by applying the stator voltages with the four-leg inverter. The switching orders are based on the comparison between the phase-voltage references and a triangular carrier wave. The switching frequency equals $10 \mathrm{kHz}$ and the dc-link voltage is equal to $270 \mathrm{~V}$. We can see that the $q$-axis current ripple is less than half of the $h$-axis current ripple. A first reason is that the time constant of the homopolar circuit is smaller than the fundamental time constant $\left(L_{h}<L_{d q}\right)$. The rise of the current is then faster in the homopolar circuit. The second is related to the VSVs and can be understood by analysing Fig. 2. Each commutation of the fourth leg leads to a change equal
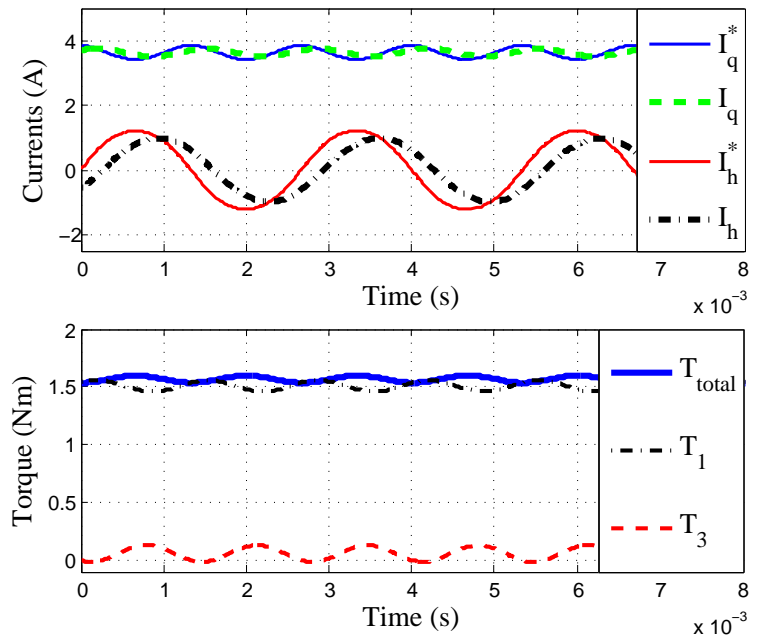

Fig. 8. Top: the $q h$ current references and the real $q h$ currents ; Bottom: EM torque produced by $q$ and $h$ currents and the sum of both; $T_{e m}^{*}=1.6 \mathrm{Nm}$; $\omega_{m}=160 \mathrm{rad} / \mathrm{s}$.

to the full dc-link voltage on the homopolar circuit while a commutation in the $\alpha \beta$ or equivalently the $d q$ plane implies vectors that are closer to the reference. Then not only the time constant is bigger, but the voltage causing this rising is lower in the $d q$ plane. But even though the homopolar current ripple is higher, the high frequency torque ripples are approximately equal as shows Fig. 10. This is due to the lower torque capability of the homopolar circuit.
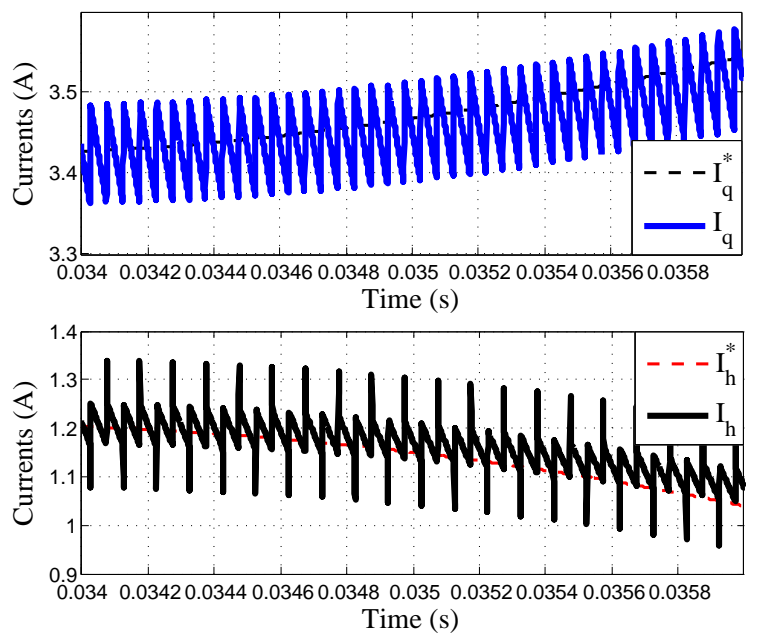

Fig. 9. Top: the $q$ current reference and the real $q$ current ; Bottom: the $h$ current reference and the real $h$ current $; T_{e m}^{*}=1.6 \mathrm{Nm}$; $\omega_{m}=16 \mathrm{rad} / \mathrm{s} ; f_{\text {switch }}=10 \mathrm{kHz} ; V_{d c}=270 \mathrm{~V}$.

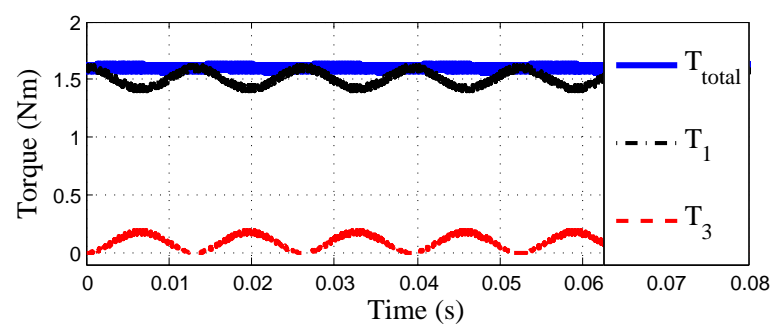

Fig. 10. EM torque produced by $q$ and $h$ currents and the sum of both $; T_{e m}^{*}=1.6 \mathrm{Nm} ; \omega_{m}=16 \mathrm{rad} / \mathrm{s} ; f_{\text {switch }}=10 \mathrm{kHz} ; V_{d c}=270 \mathrm{~V}$. 


\section{Optimization OF THE DC LinK}

Optimization of the dc-link has been studied in the past for three-phase inverter and is now being investigated for novel topologies. For example, [10] presents how to determine the optimum EMF in order to get maximum torque for a given dc-link voltage for a seven-phase PM machine.

Three-phase star connected machine supplied through a three-leg VSI only needs two DOFs for the control of the $d q$-axis currents since the homopolar current cannot flow. The remaining DOF can be used for optimizing the use of the dc-link voltage through the injection of third harmonic voltage, admitting to reach the theoritical maximum value of the fundamental phase-to-neutral voltage $V_{x, \max }=\frac{V_{d c}}{\sqrt{3}}$ (without overmodulation) as shown in Fig. 11.

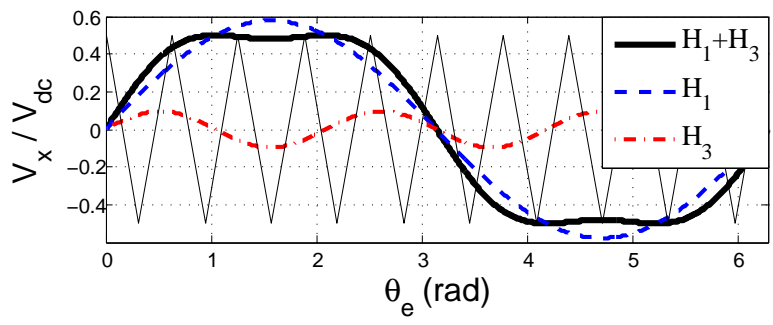

Fig. 11. Injection of $16.7 \%$ of third harmonic voltage to optimize the dc-link utilization of the three-leg inverter.

Adding a fourth leg connected to the neutral point of the machine gives us a new DOF. Three DOFs could then be used for the current control, i.e. to implement the MTPA strategy, but then it is not possible to inject third harmonic voltage anymore. The fourth degree of freedom could again be used for optimizing the use of the dc-link, but the condition is quite different. Here we take benefit of the fourth leg and the possibility to impose the neutral point voltage $V_{n}$, and by extension the differential phase voltage $\left(V_{x}-V_{n}\right)$. It is then possible to choose $V_{n}$ in such a way that the absolute value of $V_{x}$ is as much as possible lower than $\frac{1}{2} V_{d c}$. In [11], $V_{n}$ is obtained by:

$$
V_{n}=\frac{-\left(\max \left\{V_{a}, V_{b}, V_{c}\right\}+\min \left\{V_{a}, V_{b}, V_{c}\right\}\right)}{2} .
$$

This algorithm finds the maximum and the minimum of the three $a b c$ phase voltage references and symmetrizes them to allow applying up to the full dc-link voltage. Examples are given in Figs. 12 and 13 for $V_{a}=\frac{1}{\sqrt{3}} V_{d c}\left(\sin \left(\theta_{e}\right)+a \sin \left(3 \theta_{e}\right)\right)$ with $a=0$ and $a=0.41$ respectively. The $V_{x, r e f}$ voltages are referenced to the neutral point voltage $V_{n}$ while $V_{\text {diff }}$ and $V_{n}$ are referenced to the dc-link midpoint. It is interesting to note that the $a b c$ differential voltage references are exactly the same whatever the third harmonic component. It brings us to the conclusion already mentionned before that the fourleg inverter fundamental capability is exactly the same as the one of the three-leg inverter. The major difference is the third harmonic capability that is entirely linked to the fourth leg.

The ratio of $41 \%$ of third harmonic used in Fig. 13 has been chosen thanks to Fig. 6 where the peak ampitude of the EMF is plotted as a function of the parameter $a$. This ratio corresponds to the maximum value that could be useful in a machine, afterwhat it is more interesting to increase the fundamental

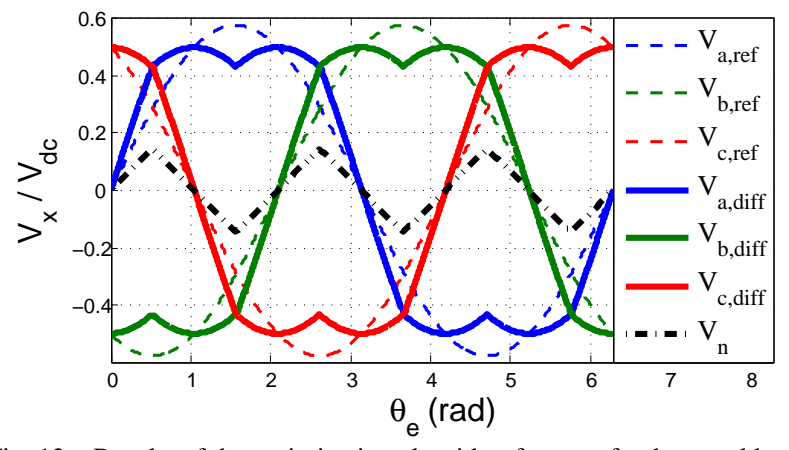

Fig. 12. Results of the optimization algorithm for pure fundamental harmonic reference voltages.

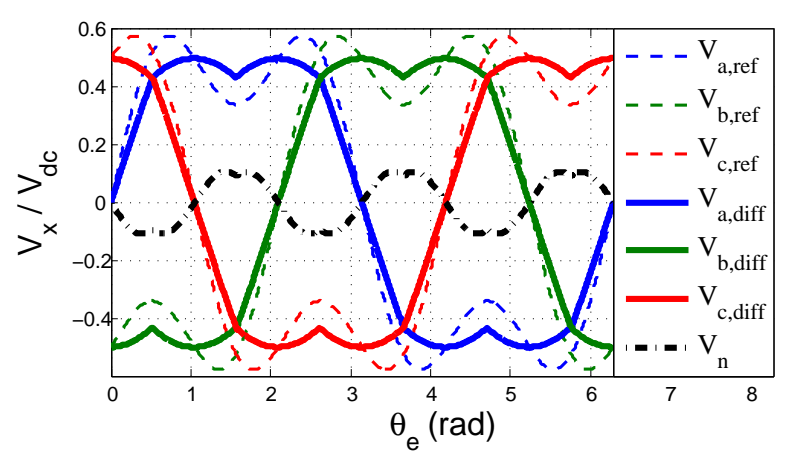

Fig. 13. Results of the optimization algorithm for the sum of a fundamental and a $41 \%$ of third harmonic voltages.

and the third harmonic together. Both curves of Fig. 6 help us to pick up two ratios that are particulary interesting. The first is the minimum of the EMF curve that shows that a $16.6 \%$ ratio of third harmonic leads to a decrease of $13.4 \%$ of the peak value of the EMF. The second ratio is $a=41 \%$ : for the same peak EMF value, the torque per ampere can be $8 \%$ higher. However, the more interesting ratio with respect to the torque increase is $16.7 \%$ because if we scale the obtained wave to reach the initial EMF value of 1, the torque increase in comparison with a completely sinusoidal machine without the MTPA strategy is: $1.01 \cdot \frac{100}{86.6} \approx 1.17$.

\section{DRIVE PERFORMANCE ENHANCEMENT}

So far, the design of the machine has not been considered but an adequate design can enhance the drive performance. In section IV, it was mentionned that for a given switching frequency the homopolar current may present a higher ripple than the $d q$ currents because of a lower time constant. This high ripple may cause overheating and has to be limited. Equation (7) shows clearly that $L_{h}$ is smaller than $L_{d q}$ if the phases possess mutual inductances. It is obvious that conventional distributed windings as shown in Fig. 14 possess mutual inductances and then could lead to low homopolar inductance value. A solution to remedy this problem could be to use a switching frequency adapted to the lower time constant but in that case the switching frequency could be excessive and the inverter losses may be too high. However, an intermediate solution is possible as we have already mentionned that the switching of the fourth leg only influences the homopolar voltage. By choosing an adequate switching scheme it is then possible to increase only the homopolar switching frequency. Fig. 15 shows an example on how to change a conventional switching scheme obtained with space 

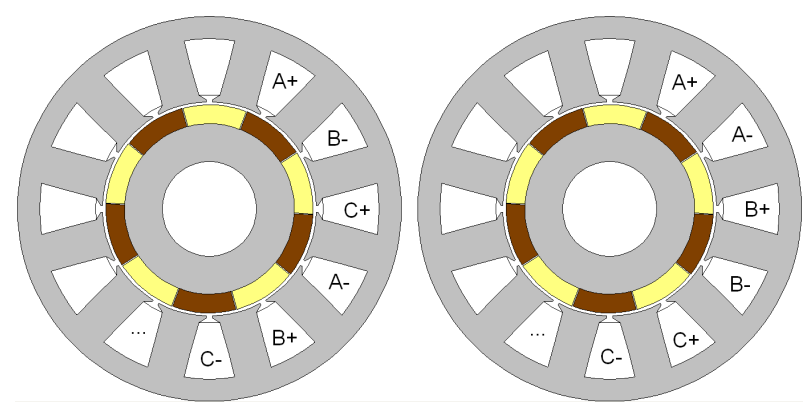

Fig. 14. Left: PMSM with conventional windings; right: PMSM with concentrated windings.

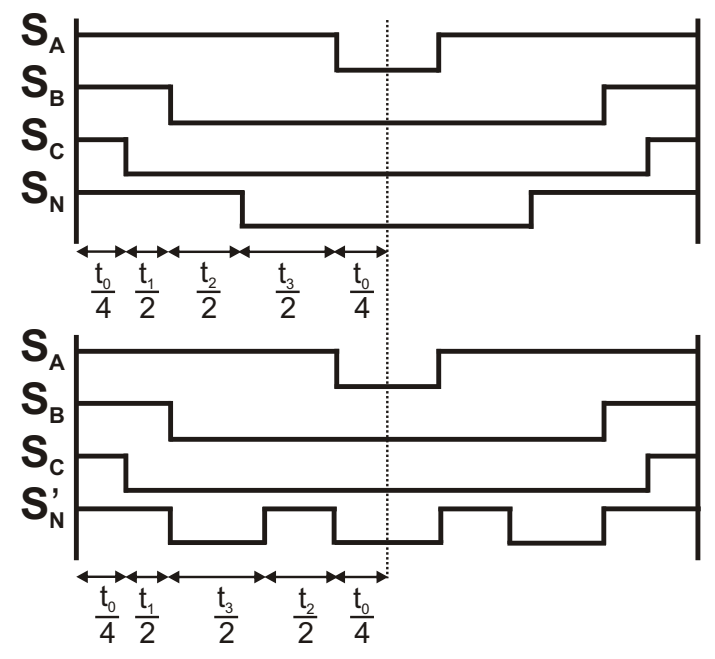

Fig. 15. Conventional SVM scheme (top) and modified to reduce the homopolar current ripple (bottom).

vector modulation (SVM) to increase the homopolar switching frequency. In fact, the conventional switching scheme imposes that each leg has one commutation by half switching period. Then we always have two consecutive vectors such as the first is XXX1 and the second is XXX0 or inversely. Exchanging their relative position in the switching scheme increases the number of commutations of the fourth leg and it only affects the homopolar circuit. The switching losses in the fourth leg will increase, but mostly $I_{n}$ will be lower than the nominal current, so the losses could be acceptable.

Rather than changing the switching scheme, a modification of the machine windings could be advantageous. Fractional concentrated windings have been investigated by several authors, [12] and [13] among others. Considering Fig. 14, it can easily be understood that this topology leads to lower mutual inductances than the conventional windings since the coils do not overlap. With this configuration, the $d q$ and $h$ axis inductances will have approximately the same value and a complexification of the switching scheme is not needed. In [14], fractional concentrated windings are used to equalize the fundamental and the third harmonic time constant of a fivephase machine.

\section{CONCLUSION}

This paper has investigated the fault-tolerant topology composed of a four-leg VSI and a three-phase PMSM in the unfaulty mode of operation. It was shown that to apply a classical $d q$ current control needs the knowledge of the EMF third harmonic component to avoid the flow of uncontrolled homopolar currents. However, the knowledge of this third harmonic EMF allows to increase the drive performance by applying the proposed maximum torque per ampere strategy, although it could imply more complex controllers than simple PI controllers for medium and high speed control. We also pointed out several third-to-first harmonic ratios that are particularly interesting and how to take benefit of the four degrees of freedom of the inverter with respect to the optimization of the dc-link utilization. In the end, a post-analysis of the simulation results proposes some possible enhancements of the switching scheme and of the machine design to increase the drive performance.

\section{ACKNOWLEDGMENT}

Fabien Meinguet would like to thank the Belgian Fund for training in Research in Industry and in Agriculture (F.R.I.A.) for the financing of this research project.

\section{REFERENCES}

[1] B. A. Welchko, T. A. Lipo, T. M. Jahns and S. E. Schulz, "Fault tolerant three-phase AC motor drive topologies: a comparison of features, cost and limitations", IEEE Trans. on Power Electronics, Vol. 19, No. 4, pp: 1108 - 1116, July 2004.

[2] B. C. Mecrow, A. G. Jack, J. A. Haylock and J. Coles, "Fault-tolerant permanent magnet machine drives", IEE Proc. on Electric Power Applications, Vol. 143, No. 6, pp: 437 - 442, November 1996.

[3] S. Bolognani, M. Zordan and M. Zigliotto, "Experimental fault-tolerant control of a PMSM drive", IEEE Trans. on Industrial Electronics, Vol. 47, No. 5, pp: 1134 - 1141, October 2000.

[4] N. Bianchi, S. Bolognani, M. Zigliotto and M. Zordan, "Innovative remedial strategies for inverter faults in IPM synchronous motor drives", IEEE Trans. on Energy Conversion, Vol. 18, No. 2, pp: 306 - 314, June 2003.

[5] C.-T. Pan and S.-M. Sue, "A linear torque per ampere control for IPMSM drives over full-speed range", IEEE Trans. on Energy Conversion, Vol. 20, No. 2, pp: 359-366, June 2005.

[6] F. M. L. L. De Belie, T. J. Vyncke, J. A. A. Melkebeek, K. R. Geldhof, L. Vandevelde and R. K. Boel, "On the influence of saturation and mutual coupling of both orthogonal magnetic axes on a MTPA controlled interior PMSM drive", 17th International Conference on Electrical Machines, OTM2-5, September 2006.

[7] R. Zhang, D. Boroyevich, V. Himamshu Prasad, H. Mao, F. C. Lee, S. Dubovsky, "A three-phase inverter with a neutral leg with space vector modulation", Proc. in Applied Power Electronics Conference and Exposition, pp: 857-863, 1997.

[8] M. J. Ryan, R. W. De Doncker and R. D. Lorenz, "Decoupled control of a 4-leg inverter via a new $4 \times 4$ transformation matrix", Proc. in Power Electronics Specialists Conference, PE-1120, June-July 1999.

[9] F. Locment, E. Semail and X. Kestelyn, "Vectorial approach based control of a seven-phase axial flux machine designed for fault operation", IEEE Trans. on Industrial Electronics, in press.

[10] F. Locment, E. Semail and X. Kestelyn, "Optimum use of DC bus by fitting the back-electromotive force of a 7-phase permanent magnet synchronous machine", Proc. of European Conference on Power Electronics and Applications (EPE), September 2005.

[11] O. Wallmark, L. Harnefors and O. Carlson, "Control algorithms for a fault-tolerant PMSM drive", IEEE Trans. on Industrial Electronics, Vol. 54, No. 4, pp: 1973 - 1980, August 2007.

[12] J. Cros and P. Viarouge, "Synthesis of high performance PM motors with concentrated windings", IEEE Trans. on Energy Conversion, Vol. 17, No. 2, pp: 248-253, June 2002.

[13] A. M. EL-Refaie and T. Jahns, "Optimal flux weakening in surface PM machines using fractional-slot concentrated windings", IEEE Trans. on Industry Applications, Vol. 41, No. 3, pp: 790-800, May-June 2005.

[14] F. Scuiller, E. Semail and J.-F. Charpentier, "Multi-criteria based design approach of multiphase permanent magnet low speed synchronous machines", IET Trans. on Electric Power Applications, in press. 